\title{
THE VALUE OF FOREST SURVEY DATA IN ESTIMATING LOGGING COST
}

\author{
By W. A. Delahey \\ International Paper Co., Ottawa
}

$\mathrm{T}^{\mathrm{H}}$

HIS is probably one of the first discussions at the Annual Meeting of the Canadian Society of Forest Engineers on "Logging Costs."

It is for this reason that I am somewhat diffident about breaking the new ground.

The following paper is of necessity brief and has been written with a view towards inviting criticism and discussion in order to bring out some facts that should be of interest to all of our members.

The past decade has seen considerable changes in the attitude of the financial controllers of the paper companies to the Forest Engineers. In most of the companies operating in Quebec the Forest Engineer has now reached the position where he has an important part to play in the planning and administration of the logging operations of his company. He is called upon not only to make forest surveys and detailed reports, but to locate cutting operations, build improvements, administer logging contracts and is responsible for the driving and delivery of logs to the mills. To sum up, he has control of the forest operations on his company's limits.

His big problem to day, in the face of trying economic conditions, is to deliver to the mill the cheapest possible wood and still comply with the funda. mentals and principles laid down in his working plans so as not to render the forest void of available cheap wood in the years to follow.

The first requisite for the solution of this problem is a reasonably accurate estimate of the cost of the wood from the various logging chances delivered at the mill.

A forester cannot think of making accurate costs estimates without first having available a complete forest survey. Risking repetition, I would again stress this point-accurate cost estimates cannot be made without the proper preliminary work, completed in terms of a comprehensive forest survey.

With the aforementioned thought in mind, let us consider briefly the forest surveys.

Ten or fifteen years ago, the main point to be considered in executing such a survey was merely an estimate of the total timber quantities broken up into broad watershed divisions. In recent years, the need of more detailed information has rapidly become apparent.

The present day forest survey, in order to supply the basic facts necessary for costs estimating must include in addition to the preparation of a general working plan, the following essential points:- 
(a) An estimate by diameter classes of the merchantable stand broken up into units sufficiently small to give an estimate for the annual cut of the average size camp.

(b) Accurate information relative to the portaging conditions and distance from the rail head. Also a discussion as to the source of labour and supplies.

(c) Stand density.

(d) Forest Type.

(e) Topography and forest bottom.

(f) Length of haul.

(g) Description of driving conditions and capacity of streams.

In the forest survey reports of ten or fifteen years ago these points were discussed in a general way. During recent years their treatment has been with a definite objective in mind, and the results therefore have been com. plete, concise and of considerable value to the operating forester. The definite object referred to is the question of cost estimating.

Now let us analyze these Forest Survey fundamentals in a little greater detail, and see how they are derived so that they can serve in the important question of cost estimating.

(a) The Timber Estimate

This is obviously the main part of forest surveying. To serve its purpose in cost estimating, it must be accurate. By accurate, I mean to within ten percent on operations as small as three hundred thousand feet. We are all familiar with the factors affecting the accuracy of a timber estimate.

Accuracy is essential in the estimate of small operating units, and although often not obtained, it can be accomplished by careful application of cruising principles.

(b) Accessibility of each Working Unit

This is usually data that can be collected without a great deal of difficulty. It is important, and should be given careful consideration.

(c) Stand Density

It is my experience that estimates, in addition to being shown in tabular form, have an immense value if shown graphically by their stand per acre, plot location on the map. This information is particularly valuable to the field men.

(d) Forest Type

I need not discuss before this gathering the part that forest type plays in determining the silvicultural system to be applied. 
(e) Topography and forest bottom

For the most part, in the province of Quebec, it is not economic to prepare a contour map. Topography and swamping conditions must therefore be furnished in the report by brief, concise, descrip. tion.

(f) Length of Haul

This information is obtained from the map.

(g) Driving

I think I am correct in saying that foresters are more and more realizing the necessity, while carrying out their forest surveys, of providing for the collection of detailed information on the factors affecting driving costs. I refer particularly to stream capacity and the location, extent and approximate cost of stream improvements.

In the foregoing paragraphs, the data to be collected and compiled have been outlined very briefly.

Coming more definitely to the question of logging costs one finds that whilst there may be some differences between the set-up of the cost structure for the different companies, most companies' costs will be found to give the same information, although often under different headings or classifications.

Before going further into this discussion, I would mention that wage rates and commodity prices will be disregarded. This can readily be accomplished without detracting from the value of my remarks, insomuch as the essentials of logging costs can be expressed in terms of man and horse day production.

Roughly, operating logging costs can be classified into two main headings which are:-

1. Controllable Costs.

2. Non-Controllable Costs.

Non-controllable items, in which, in this discussion, we are not interested, include such items as stumpage, ground rent, forest protection, insurance, taxes, rental, etc., etc.

The Controllable items include the variables, and it is in this class of logging costs in which the forester finds a fertile field for his energy and activities.

In most companies' cost set-up, all costs except those of the jobbers' "Cost of wood on landings," are, or can be broken down in great detail. In cases of companies operating company camps, the cost of wood on landings is kept in considerable detail but as it is common practice in Quebec for the majority of operators to have their logging carried out by jobbers, the remaining paragraphs refer particularly to companies employing the latter mode of operating.

As previously stated, it is the Controllable costs in which the Forest 
Engineer is interested and these can be grouped under the following headings:

1. Jobbers' Cost of Wood on Landings.

2. Improvement Write-offs and salaries and expenses of Headquarters offices.

3. Depot expense, Portaging Costs, etc., etc.

4. Driving Costs.

$\mathrm{He}$ will also be interested in the overhead cost, but to a lesser extent excepting for those charges in the wood costs which originate from forest engineering expenditures.

The big item in woods costs and the one in which the forest engineer can be of most service to his company in helping to control is that of jobbers' Cost of Wood on Landings. This item makes up from 35 to $45 \%$ of the total cost of delivering logs from the woods to the jack ladder.

Assuming efficient management, the factors governing this part of the cost are those that were outlined a few minutes ago and are repeated as follows:

(a) Location of cutting area in relation to rail head.

(b) Stand Density.

(c) Forest Types.

(d) Topography and forest bottom.

(e) Length of haul.

Information on all these factors will have already been compiled in the original forest survey. The original investigation, however, must be followed up, immediately in advance of the operation, by a more detailed study of conditions on the ground. This study can only be accomplished by a careful examination of each logging chance.

The definite part that each of these factors play in cost estimating is more or less apparent. However, I think it will be in order here to discuss them briefly.

The location of the cutting area in relation to the rail head governs the delivered cost to the camp of food and fodder supplies, which, in turn, affects the cost of feeding men and horses. In this connection it is well to bear in mind that the cost of man and horse meals constitute slightly under one-third of the total "Stump to Landing" cost.

The density of the timber expressed as stand per acre, influences directly the cost of yarding, and governs the amount of branch haul road to be constructed. These two cost items also vary with the size of the trees and the subsequent log run.

Topography and swamping conditions determine the logging technique to be used. 
As previously mentioned, the forest types encountered determine the silvicultural system to be employed.

Hauling, of course, makes up a large part of delivered cost of the wood. Information should be available for each logging chance to show the average length of haul within oneeight of a mile. The total miles of main and branch haul road must be known. The collection of this latter data constitutes the main part of the final examination on the ground, immediataely preceding the operation.

I have already pointed out, in my earlier remarks, the need of accurate data on the factors influencing driving costs.

To prepare estimated logging costs of wood on landing requires not only the foregoing information, but statistical information compiled from experience over several years. These "Experience figures" should be compiled year after year until the values repeat and cannot be further refined. The following sub-divisions under which the statistical information should be compiled are suggested:

1. Yarding.

2. Hauling.

3. Haul road construction.

4. Camp construction.

5. Miscellaneous supplies.

6. Cookery and Camp help.

7. Transportation.

8. Exploration.

9. Preparation of dumps, landings and booming where necessary.

10. Clerical overhead.

11. Idle Time.

In the list just cited, items one and two, and these are the most important, are expressed in term of production per man day and per horse day. The first varies with stand per acre and size of timber, while the second varies with the average hauling distance. Items three and four are expressed in terms of man and horse labour varying with the influencing factors. Item five is an experience figure expressed as averages per thousand feet. The remaining items are estimated in their total amount, based on past experience and a knowledge obtained on the ground of the obvious influencing factors.

Definite instructions should be drawn up so that uniform information will be collected throughout the various operations by any particular company. The report forms on which the information is to be returned should be very carefully prepared in advance. The actual collection of the information under these classifications can be very well taken care of by the inspectors in the 
field whilst they are carrying out their regular inspection duties on the cutting areas to enforce the Company and Government Regulations.

With this statistical information correlated with the data contained in the forest engineers' reports, it will not be a difficult matter to prepare accurate cost estimates for all logging chances on any company's limits. On the other hand, and I want to particularly stress the point,-it is absolutely essential to have first hand knowledge of the country obtained by travel on the ground.

It is assumed of course that detailed information is also available to show food consumption per man per day and fodder consumption per horse per day. This information along with the wage rates and the commodity prices for any one year will be all that will be required to prepare the estimates.

In the foregoing no attempt has been made to discuss costs other than those affecting the cost of the wood from stump to landing. It is not for a minute suggested that the Forest Engineer is not interested in the other costs. The reasons for emphasizing this particular division of costs is that too often in the past this important phase of operating cost has been neglected. A study of the card of accounts for any particular company and a visit to the chief accountant by any Forest Engineer will certainly be time well spent. One will learn that the accounting system is elastic and that by studying the costs along with the accountant, one can get reasonable detailed information for any part of the delivered costs of logging except that as outlined above.

In these brief remarks no attempt has been made to give a complete analysis of logging cost accounting. I have merely attempted to touch briefly on the more important points relative to estimating of logging cost.

Before closing I want to make a few remarks regarding another factor which plays an important part in the cost of logging and which has been neglected in the past. I refer to "Workmen's Compensation." A very excellent paper on this subject was delivered by Mr. J. E. Rothery, of New York, for the meeting of the National Safety Council in Washington on October 6th, last. Copies of this paper were distributed to members of the Woodlands Section of the Pulp and Paper Association and the information and recommendations contained therein should be of interest to all Forest Engineers, not only from the cost, but the humanitarian point of view. The expenditures on Workmen's Compensation too often in the past have been treated as a necessary evil with little thought as to how they could be reduced. In recent years compensation costs have been increasing and it is only now that company executives are paying much attention to this important item. This indifferent attitude has existed in spite of the excellent work done and recommendations of such men as Dr. Barnhart, of Ottawa, and the doctors who have been employed on operations by many companies. 
It is suggested here that Forest Engineers should give considerable thought to accident preventions because after all, if they are really practicing forestry they are in close contact with the workmen in the woods. It is also recommended that all Forest Engineers can be of real service in reducing this part of logging costs and also that all should have a good working knowledge of administering "First Aid."

In closing, I wish to express my appreciation to Messrs. F. R. Wilcox and W. A. E. Pepler for the help and co-operation that they gave to me in the preparation of this paper.

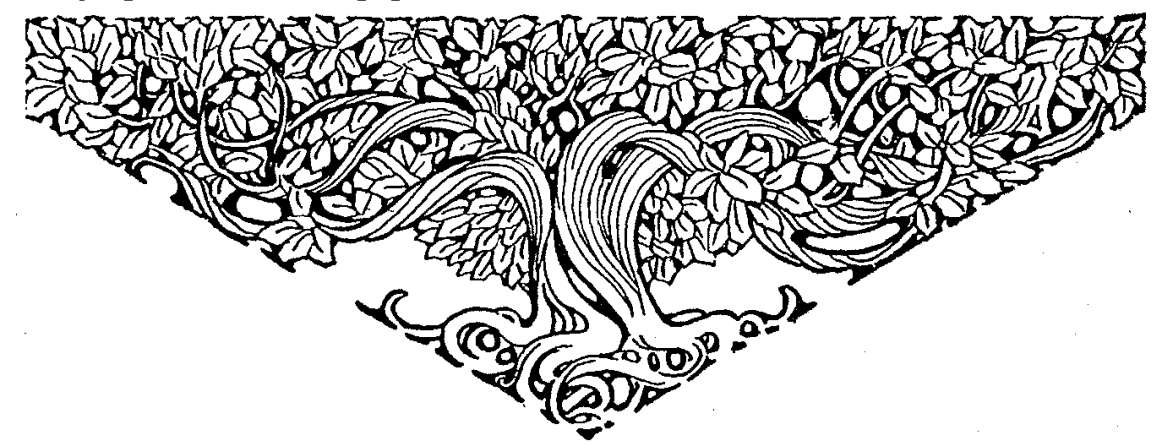

